\title{
Characteristics and outcomes of patients admitted to regional and rural intensive care units in Australia
}

Paul Secombe, Alex Brown, Michael Bailey, Edward Litton and David Pilcher

www.doi.org/10.51893/2020.4.0a6

Published online first 7 December 2020

Regional and rural Australia - that is, those areas that lie outside the major capital cities - is home to over 8 million people (33\% of the total population), and comprises about $98 \%$ of the Australian land mass. ${ }^{1,2}$ The health of regional Australians is poorer than their city counterparts. They die at a younger age, carry a higher burden of chronic disease, and are more likely to engage in unhealthy behaviours. ${ }^{3}$ Such findings are not unique to Australian regional and rural populations. ${ }^{4}$ They also have less access to and are less likely to seek medical services. ${ }^{5}$ It has recently been hypothesised that some of the misrepresentations of Aboriginal and Torres Strait Islander (Indigenous) Australians in the intensive care unit (ICU) are also due to access barriers to both primary and subspecialty care. ${ }^{6}$

Specialist medical facilities, including ICUs, are clustered in areas of high population density, mostly in and around capital cities. These tertiary and metropolitan ICUs provide highly efficient critical care services to people living in the major cities of Australia, but this aggregation of ICUs may be problematic for critically ill regional and rural Australians. ${ }^{7}$

Despite population and health service differences, comparative data on the provision of critical care services in Australia by regional and rural ICUs are lacking. A description of the characteristics and outcomes of critically ill patients admitted to regional and rural ICUs may help to identify whether equity exists in the provision of ICU care and highlight the role of regional and rural ICUs in the management of critically ill Australians. It was hypothesised that the outcomes of regional Australians admitted for critical illness would mirror the higher mortality observed in regional areas.

\section{Methods}

The Australian and New Zealand Intensive Care Society (ANZICS) Adult Patient Database (APD), one of four clinical quality registries administered by the ANZICS Centre for Outcome and Resource Evaluation (CORE), was used. The

\begin{abstract}
Objective: To describe the characteristics and outcomes of patients admitted to regional and rural intensive care units (ICUs).
\end{abstract}

Design, setting and participants: Retrospective database review using the Australian and New Zealand Intensive Care Society Adult Patient Database for admissions between January 2009 and June 2019. Characteristics and outcomes of patients admitted to regional and rural ICUs were compared with metropolitan and tertiary ICUs.

Main outcome measures: Primary outcome was hospital mortality. Secondary outcomes included patient characteristics, ICU mortality, ICU and hospital length of stay, need for mechanical ventilation and need for interhospital transfer.

Results: Over the sampling period, admissions to regional/ rural ICUs averaged nearly 19000 episodes per annum and comprised $20 \%$ of critical care admissions in Australia. Unadjusted mortality was lower, a result that persisted after adjustment for a range of confounders (odds ratio, 0.73; $95 \% \mathrm{Cl}, 0.67-0.80 ; P<0.01)$. Admissions are more likely to be emergencies, and patients are more likely to live in areas of relative disadvantage and to require interhospital transfer, but are less likely to require mechanical ventilation. Conclusions: Although illness severity is lower for patients admitted to regional/rural ICUs, hospital mortality after adjustment for a range of confounders is lower. Compared with tertiary ICUs, emergency admissions are more likely, which may have implications for surge capacity during pandemic illness, while mechanical ventilation is less frequently required. Regional/rural ICUs provide care to a substantial proportion of critically ill patients and have a crucial role in the support of regional Australians.

Crit Care Resusc 2020; 22 (4): 335-343 


\section{ORIGINAL ARTICLES}

APD was used to identify all patients aged 16 years or older admitted to an Australian public ICU between 1 January 2009 and 30 June 2019. Over 90\% of ICU admissions in Australia are reported to the APD. ${ }^{8}$ ICUs are classified by the type of hospital to which they provide services (tertiary, metropolitan, regional/rural or private).

Admissions were excluded if there was no admission diagnosis, no in-hospital mortality outcome listed, or if the admission was to a private ICU. To avoid double-counting patient outcomes, ICU readmissions during the same hospital episode were excluded, as were episodes where the admission source was the ICU of another hospital (ie, an interhospital transfer $[\mathrm{IHT}]$ defined by the receiving $\mathrm{ICU}$ ). Patients readmitted to ICU at the same hospital in a separate hospital episode were included and considered as two distinct episodes. It was not possible to identify subsequent ICU admissions at a different hospital. The study was approved by the Central Australian Human Research Ethics Committee (CA-19-3516) and was conducted following the Strengthening the Reporting of Observational studies in Epidemiology (STROBE) standards (Online Appendix, table 1). ${ }^{9}$

Baseline characteristics (age and sex), demographic features (home postcode, regional status), the presence of comorbidities, the need for mechanical ventilation, and outcomes were extracted. ${ }^{10}$ Illness severity was described using the Acute Physiology and Chronic Health Evaluation (APACHE) II and III scoring systems and the Australian and New Zealand Intensive Care Risk of Death (ANZROD) model. ${ }^{11-13}$ ANZROD is derived from locally collected variables and components of the APACHE scoring system. It accounts for individual admission diagnoses and applies separate predictive equations for each major physiological system. It provides highly discriminatory mortality prediction for admissions to Australian and New Zealand ICUs. ${ }^{13}$ The reason for ICU admission was taken from the ANZICS modification of the APACHE III diagnostic coding system. ${ }^{10}$ Individual admission diagnoses were grouped into eight major system-based categories.

Remoteness and socio-economic status were determined respectively by the 2011 iteration of the Accessibility and Remoteness Index of Australia (ARIA+) and the 2011 iteration of the Index of Relative Socio-Economic Advantage and Disadvantage (IRSAD) linked to each patient's postcode. ${ }^{14,15}$ ARIA+ is an objective process for classifying remoteness and values vary between 0 (high accessibility) and 15 (high remoteness) based on road distance measurements, population size, and accessibility. ${ }^{15}$ IRSAD is a general socio-economic index that summarises the economic and social conditions within an area. Lower numbers indicate areas of relative greater socio-economic disadvantage and lack of advantage. ${ }^{14}$
The primary outcome was in-hospital mortality. Secondary outcomes included in-ICU mortality, measures of resource use (ICU and hospital length of stay, need for mechanical ventilation, need for $(\mathrm{HT})$, and ICU readmissions rate in subsequent hospital admissions.

\section{Statistical analysis}

Data were analysed with STATA version 15.1 (Statacorp, Texas, USA). All data were initially assessed for normality. Group comparisons were performed using $\chi^{2}$ tests, Student $t$ test for normally distributed data, and Wilcoxon rank sum tests for non-normally distributed data. Results are reported as $n(\%)$, mean (standard deviation [SD]) or median (interquartile range [IQR]) respectively. Hierarchical logistic regression was used to account for baseline severity of illness using ANZROD methodology, adjusting for hospital type, region, year of admission (treated as a continuous variable) and socio-economic status, with patients clustered by site, and site treated as a random effect. ${ }^{13}$ To reduce the risk of confounding due to an $\mathrm{IHT}$ (since attribution of mortality may be transferred from the regional or rural ICU to a tertiary ICU), further sensitivity analyses were undertaken excluding patients who had an ICU discharge destination of another ICU and also without excluding any $\mathrm{IHT}$. For comparative analyses, $P$ values are provided for perspective rather than for statistical significance; and for regression, results were considered significant at $P<0.05$.

\section{Results}

\section{Patient characteristics}

Between January 2009 and July 2019, there were nearly 1.4 million admissions to adult ICUs within Australia reported to the ANZICS APD. After exclusions (Figure 1), the study dataset comprised 876522 episodes of care in 103 distinct ICUs, of which 172444 (19.7\%) occurred in one of 36 regional/rural units (Table 1). The proportion of admissions to regional/rural units over the sampling period was relatively stable (Figure 2). Patients admitted to regional/rural units were less likely to originate from a major city, had a higher ARIA+ score, indicating a residential postcode from more remote centres, and were more likely to come from areas that were relatively disadvantaged and had less advantage.

Patients admitted to a regional/rural ICU had a similar age $(62.5 \vee 63.9 \vee 64.6$ years for tertiary, metropolitan and regional/rural ICUs respectively), and were more frequently admitted emergently (64.5\% v81.7\% v81.1\% respectively). They more frequently had chronic cardiovascular or chronic respiratory disease and less frequently had metastatic cancer, leukaemia, or were immunosuppressed (Table 1). 


\section{ORIGINAL ARTICLES}

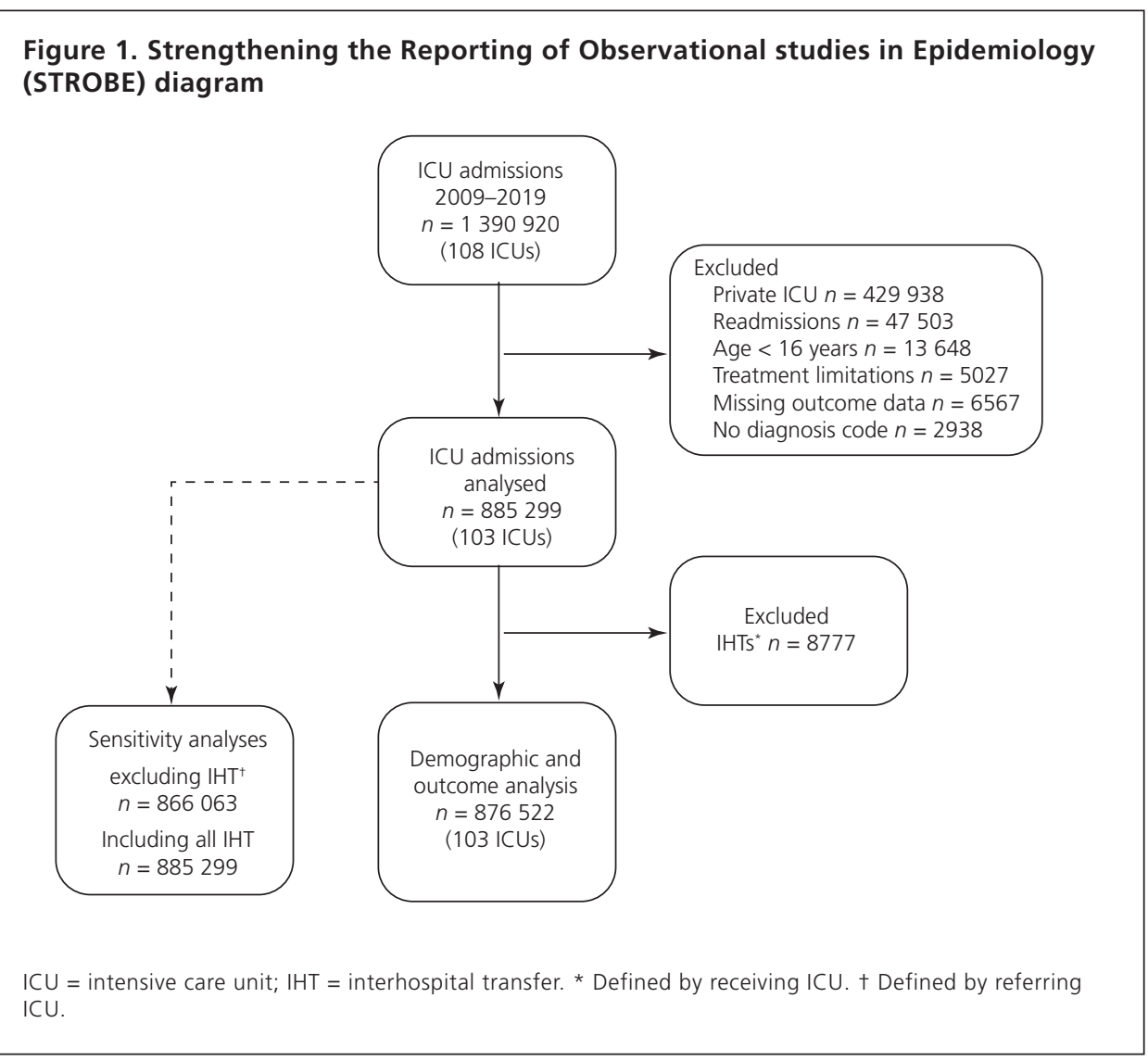

days for tertiary, metropolitan and regional/rural ICUs respectively). Patients admitted to regional/ rural ICUs had lower rates of mechanical ventilation $(51.7 \%$ $v 30.5 \%$ v $19.9 \%$ for tertiary, metropolitan and regional/rural respectively), although about onethird of ventilated patients were elective ICU admissions (Online Appendix, table 4). Admissions to regional/rural ICUs were more likely to result in an IHT from the unit to which they presented to a unit that offered a higher level of care. There were significantly more admissions to regional/rural ICUs that represented an ICU episode during a subsequent hospital admission; indeed, this was nearly twice as likely compared with tertiary hospitals.

\section{Discussion}

Nearly $20 \%$ of ICU admissions in Australia occur to regional/rural

Illness severity was lower in regional/rural units, with lower APACHE II and III scores and lower risk of death as measured by ANZROD. Admission diagnoses for cardiovascular, respiratory or gastrointestinal reasons predominated in regional/rural units, while an admission following cardiac surgery was rare.

\section{Outcomes}

Unadjusted hospital mortality was lower in regional/rural ICUs $(10.7 \% \vee 10.5 \% \vee 8.0 \%$ for tertiary, metropolitan and regional/rural ICUs respectively) (Table 2), a finding that persisted after adjustment for illness acuity, socio-economic disadvantage, jurisdiction, and year of admission (odds ratio $[\mathrm{OR}], 0.73 ; 95 \% \mathrm{Cl}, 0.66-0.80 ; P<0.001$ ) (Figure 3). The full model is outlined in Table 3 . Sensitivity analysis excluding patients who had an ICU discharge destination of another ICU (an IHT defined by the referring unit) and including all patients irrespective of retrieval status revealed similar results (Online Appendix, tables 2 and 3).

Unadjusted ICU mortality was lowest in regional/rural ICUs (7.0\% $\vee 6.5 \% \vee 5.0 \%$ of tertiary, metropolitan and regional/ rural ICUs respectively). There were very small differences in ICU length of stay, with the longest seen for patients admitted to metropolitan ICUs (Table 2). Hospital length of stay was shorter in regional/rural hospitals $(10.0 \vee 7.4 \vee 6.0$
ICUs. Admissions are more frequently emergencies than to tertiary ICUs and illness severity is slightly less than that of metropolitan and tertiary ICUs, while ICU readmissions in subsequent hospital episodes is nearly twice that of tertiary ICUs. Unadjusted mortality following an ICU admission in a regional/rural ICU is lower than both metropolitan and tertiary ICUs, and this finding persists after adjusting for illness severity and other potential confounders. These findings are topical, given media reporting about the quality of health care delivered at regional hospitals. ${ }^{16}$

The lower mortality rate seen in regional/rural units may have several explanations. First, it may be as a result of residual confounding. Second, there could be a real relationship between remoteness and mortality such that there is a protective effect, although the evidence is contradictory and the association between remoteness and any mortality benefit are likely complex and multifactorial. 3,4,17-21 This signal, at least within the critical care literature, appears to be robust and warrants further research. ${ }^{21}$ Third, it is possible that the sickest patients in remote regions die before admission to an ICU because of longer transfer times or through a lack of timely access to appropriate critical care services. ${ }^{22-24}$ Fourth, there may be less pressure to admit patients who are unlikely to survive to regional/rural ICUs. Fifth, the higher mortality reported 


\section{ORIGINAL ARTICLES}

Table 1. Baseline characteristics of Australian patients admitted to the intensive care unit (ICU) by type of ICU (rural $v$ metropolitan $v$ tertiary)*

\begin{tabular}{|c|c|c|c|c|}
\hline & $\begin{array}{c}\text { All } \\
\text { (106 contributing } \\
\text { ICUs) }\end{array}$ & $\begin{array}{c}\text { Rural } \\
\text { (6 contributing ICUs) }\end{array}$ & $\begin{array}{l}\text { Metropolitan } \\
\text { (33 contributing } \\
\text { ICUs) }\end{array}$ & $\begin{array}{c}\text { Tertiary } \\
\text { (34 contributing } \\
\text { ICUs) }\end{array}$ \\
\hline Total number of episodes of care & 876522 & 172444 & 197659 & 506419 \\
\hline Median age (IQR), years & $63.1(47.9-74.4)$ & $64.6(48.4-75.8)$ & $63.9(47.2-75.8)$ & $62.5(48.0-73.3)$ \\
\hline Male sex ${ }^{+}$ & $505965(57.7 \%)$ & $93107(54.0 \%)$ & $103871(52.6 \%)$ & $308987(61.0 \%)$ \\
\hline \multicolumn{5}{|l|}{ Remoteness } \\
\hline Major city & $482227(55.6 \%)$ & $10979(6.3 \%)$ & $14685(72.0 \%)$ & $325063(66.3 \%)$ \\
\hline Inner regional & $225728(26.0 \%)$ & $85289(49.2 \%)$ & $40924(20.2 \%)$ & $99515(20.3 \%)$ \\
\hline Outer regional & $126311(14.6 \%)$ & $63383(36.6 \%)$ & $11741(5.8 \%)$ & $51187(10.4 \%)$ \\
\hline Remote & $16315(1.9 \%)$ & $6815(3.9 \%)$ & $872(0.4 \%)$ & $8628(1.8 \%)$ \\
\hline Very remote & $16692(1.9 \%)$ & $6929(4.0 \%)$ & $3347(1.7 \%)$ & $6416(1.3 \%)$ \\
\hline Median ARIA ${ }^{\ddagger}$ score (IQR) & $0.11(0-1.8)$ & $2.0(1.2-3.2)$ & $0.01(0-0.3)$ & $0(0-0.9)$ \\
\hline Median IRSAD (IQR) & $972(933-1031)$ & 947 (914-968) & $984(935-1036)$ & $992(941-1050)$ \\
\hline Emergency admission ${ }^{\S, q}$ & $623207(71.7 \%)$ & $139264(81.1 \%)$ & $160330(81.7 \%)$ & $323613(64.5 \%)$ \\
\hline Medical response team ${ }^{\S, * \star}$ & $90579(11.2 \%)$ & $18559(11.1 \%)$ & $24292(12.7 \%)$ & $47728(10.6 \%)$ \\
\hline $\begin{array}{l}\text { Median hours preceding ICU } \\
\text { admission (IQR) }\end{array}$ & $8.5(3.8-26.4)$ & $6.9(3.7-16.3)$ & $7.7(3.3-22.0)$ & $9.8(4.1-30.8)$ \\
\hline ICU§ & $639506(72.1 \%)$ & $79006(44.9 \%)$ & $142785(68.9 \%)$ & $417715(82.8 \%)$ \\
\hline \multicolumn{5}{|l|}{ Chronic disease status $^{\S}$} \\
\hline Respiratory & $74849(8.4 \%)$ & $20842(11.9 \%)$ & $23983(11.6 \%)$ & $30024(6.0 \%)$ \\
\hline Cardiovascular & $73964(8.3 \%)$ & $20711(11.8 \%)$ & $21914(10.6 \%)$ & $31339(6.2 \%)$ \\
\hline Cirrhosis & $20644(2.3 \%)$ & $3651(2.1 \%)$ & $4928(2.4 \%)$ & $12065(2.4 \%)$ \\
\hline Renal & $33159(3.7 \%)$ & $8745(5.0 \%)$ & $7987(3.9 \%)$ & $16427(3.3 \%)$ \\
\hline Immunosuppression & $57742(6.5 \%)$ & $7796(4.4 \%)$ & $9515(4.6 \%)$ & $40431(8.0 \%)$ \\
\hline Lymphoma & $7983(1.0 \%)$ & $1122(0.6 \%)$ & $1796(0.9 \%)$ & $5065(1.0 \%)$ \\
\hline Metastatic disease & $30930(3.5 \%)$ & $4420(2.5 \%)$ & $6834(3.3 \%)$ & $19676(3.9 \%)$ \\
\hline Leukaemia & $10303(1.2 \%)$ & $1235(0.7 \%)$ & $2018(1.0 \%)$ & $7050(1.4 \%)$ \\
\hline Median APACHE II score (IQR) & $15(11-21)$ & $14(9-20)$ & $16(11-22)$ & $15(11-21)$ \\
\hline Median APACHE III score (IQR) & $51(36-69)$ & $46(32-64)$ & $53(38-72)$ & $52(38-70)$ \\
\hline Mean ANZROD (SD) & $10.1 \pm 17.7$ & $9.2 \pm 16.0$ & $10.8 \pm 17.9$ & $10.1 \pm 18.0$ \\
\hline Median ANZROD (IQR) & $2.6(0.8-10.0)$ & $2.7(0.8-9.0)$ & $3.2(0.9-11.3)$ & $2.4(0.7-9.7)$ \\
\hline \multicolumn{5}{|l|}{ Admission diagnosis ${ }^{\ddagger}$} \\
\hline Cardiological & $100438(11.3 \%)$ & $21703(12.3 \%)$ & $24182(11.7 \%)$ & $54553(10.8 \%)$ \\
\hline Cardiac surgery & $101208(11.4 \%)$ & $644(0.4 \%)$ & $2762(1.3 \%)$ & $97802(19.4 \%)$ \\
\hline Respiratory & $147481(16.6 \%)$ & $35632(20.3 \%)$ & $44337(21.4 \%)$ & $67512(13.4 \%)$ \\
\hline Gastrointestinal & $144448(16.3 \%)$ & $36208(20.6 \%)$ & $42165(20.3 \%)$ & $66075(13.1 \%)$ \\
\hline Neurological & $92332(10.4 \%)$ & $11789(6.7 \%)$ & $11294(5.5 \%)$ & $69249(13.7 \%)$ \\
\hline Sepsis & $76606(8.6 \%)$ & $17659(10.0 \%)$ & $22017(10.6 \%)$ & $36930(7.3 \%)$ \\
\hline Trauma & $55881(6.3 \%)$ & $9021(5.1 \%)$ & $5100(2.5 \%)$ & $41760(8.3 \%)$ \\
\hline Other & $169222(19.1 \%)$ & $43209(24.6 \%)$ & $55414(26.7 \%)$ & $70559(14.0 \%)$ \\
\hline Mechanically ventilated & $358944(40.4 \%)$ & $34983(19.9 \%)$ & $63166(30.5 \%)$ & $260795(51.7 \%)$ \\
\hline
\end{tabular}

ANZROD Australian and New Zealand Risk of Death; APACHE = Acute Physiology and Chronic Health; ARIA+ = Accessibility and Remoteness Index (2011 iteration); IRSAD = Index or Relative Socio-economic Advantage and Disadvantage (2011 iteration). ${ }^{*} P<0.001$ for all. + Data available for 876357 episodes of care (tertiary, $n=506343$; metropolitan, $n=197595$; rural, $n=172$ 419). $\neq$ Available for episodes of care with postcode data ( $n=870054$; tertiary, $n=491656$; metro, $n=204$ 098; rural, $n=174$ 300). § Defined by ANZICS APD data dictionary. I Data available for 869471 episodes of care (tertiary, $n=501$ 540; metropolitan, $n=196$ 160; rural, $n=171$ 771). ** Data available for 807549 episodes of care (tertiary, $n=45017$; metro, $n=190875 ;$ rural, $n=166657$ ). 


\section{ORIGINAL ARTICLES}

Figure 2. Proportion of admissions to regional/rural, metropolitan and tertiary intensive care units over the sampling period

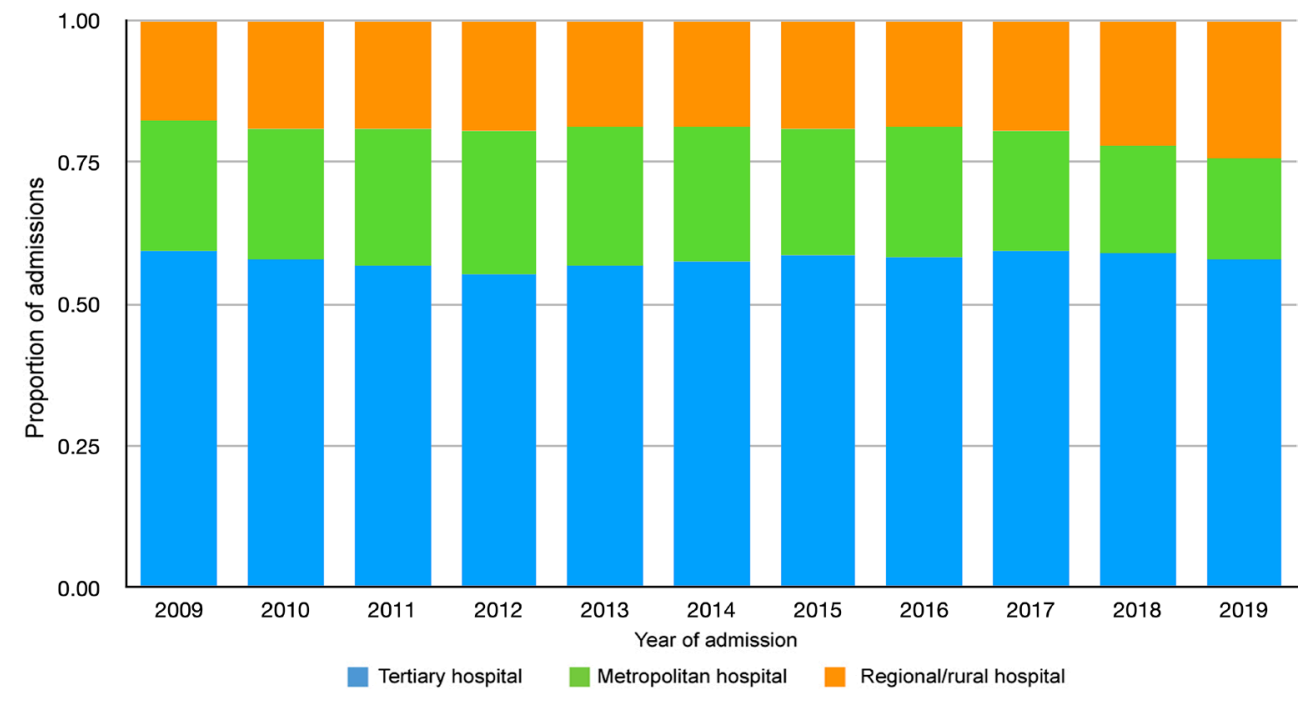

Sixth, it is possible that patients admitted to a regional/rural ICU receive high quality largely consultant-delivered care, which results in improved outcomes. Finally, it is possible that patients with a higher risk of mortality are being transported to a tertiary centre after initial stabilisation at a regional/ rural ICU. However, the latter explanation is unlikely to explain the lower mortality, given the robustness of the adjusted mortality outcome on sensitivity analyses.

The higher frequency of emergency admissions to both regional/rural and metropolitan ICUs are

in regional/rural areas appears to be mostly attributable to chronic disease progression. ${ }^{3}$ These data support the hypothesis that critical illness does not contribute markedly to the observed mortality difference between regional/rural populations and their major city counterparts. ${ }^{3,25}$ There is some emerging evidence of this, albeit mostly in small single centre observational studies, seemingly suggesting that once admitted to an ICU mortality, equivalence exists. ${ }^{21,23,26,27}$ thought to reflect the rates of high risk elective surgery undertaken in tertiary centres (predominantly elective cardiac surgery), and through the relatively lower rate of elective post-operative admission diagnosis, probably also contributed to the lower rates of mechanical ventilation in both regional/rural and metropolitan ICUs. The high proportion of patients admitted emergently, however, highlights the lack of surge capacity that could be recruited

\section{Table 2. Outcomes*}

\begin{tabular}{lcccc} 
& All & $\begin{array}{c}\text { Regional/rural } \\
\text { hospital }\end{array}$ & $\begin{array}{c}\text { Metropolitan } \\
\text { hospital }\end{array}$ & Tertiary hospital \\
\hline Total number of episodes of care & 876522 & 172444 & 197659 & 506419 \\
\hline $\begin{array}{l}\text { Primary outcome } \\
\quad \text { Hospital mortality }\end{array}$ & $88656(10.1 \%)$ & $13783(8.0 \%)$ & $20748(10.5 \%)$ & $54125(10.7 \%)$ \\
$\begin{array}{l}\text { Secondary outcomes } \\
\text { ICU mortality }\end{array}$ & $57384(6.6 \%)$ & $8962(5.0 \%)$ & $13109(6.6 \%)$ & $35583(7.0 \%)$ \\
Median ICU LOS (IQR), days ${ }^{\dagger}$ & $1.86(0.95-3.67)$ & $1.84(0.93-3.48)$ & $1.87(0.96-3.67)$ & $1.85(0.95-3.74)$ \\
$\quad$ Median hospital LOS (IQR), days ${ }^{\dagger}$ & $8.44(4.61-16.16)$ & $6.00(2.87-11.29)$ & $7.44(3.8-14.39)$ & $9.99(5.78-18.66)$ \\
Interhospital transfer & $41652(4.8 \%)$ & $19021(11.0 \%)$ & $10695(5.4 \%)$ & $11936(2.4 \%)$ \\
ICU readmission & $112225(14.2 \%)$ & $31772(20.0 \%)$ & $28487(16.1 \%)$ & $50467(11.2 \%)$ \\
\hline
\end{tabular}

ICU = intensive care unit; IQR = interquartile range; LOS = length of stay. ${ }^{*} P<0.001$ for all. + Stratified by hospital survival $(n=787866$; rural, $n=158$ 661; metropolitan, $n=176$ 911; tertiary, $n=452$ 294) - represents episode data. $\neq$ Readmission to the ICU in a subsequent hospital episode. 


\section{ORIGINAL ARTICLES}

Table 3. Hierarchical logistic regression model*

\begin{tabular}{|c|c|c|c|c|}
\hline & $n$ & $\begin{array}{c}\text { Deaths } \\
n(\%)\end{array}$ & $\begin{array}{l}\text { Odds ratio } \\
(95 \% \mathrm{Cl})\end{array}$ & $P$ \\
\hline \multicolumn{5}{|l|}{ Severity of Illness } \\
\hline ANZROD (log) & 871301 & $88027(10.1 \%)$ & $3.8(3.74-3.80)$ & $<0.001$ \\
\hline \multicolumn{5}{|l|}{$\begin{array}{l}\text { Socio-economic } \\
\text { status }\end{array}$} \\
\hline IRSAD & 858752 & $86752(10.1 \%)$ & $1.00(1.0-1.0)$. & 0.25 \\
\hline \multicolumn{5}{|l|}{$\begin{array}{l}\text { Hospital } \\
\text { Classification }\end{array}$} \\
\hline Tertiary & 506419 & $54125(10.7 \%)$ & Reference & \\
\hline Metropolitan & 197659 & $20748(10.5 \%)$ & $0.84(0.77-0.92)$ & $<0.001$ \\
\hline Rural/regional & 172444 & $13783(8.0 \%)$ & $0.73(0.67-0.80)$ & $<0.001$ \\
\hline \multicolumn{5}{|l|}{ Year of admission } \\
\hline Admission year & 876522 & $88656(10.1 \%)$ & $0.97(0.97-0.97)$ & $<0.001$ \\
\hline \multicolumn{5}{|l|}{ Jurisdiction } \\
\hline $\mathrm{ACT}$ & 25523 & $2701(10.6 \%)$ & Reference & \\
\hline NSW & 307858 & 32747 (10.6\%) & $0.90(0.69-1.18)$ & 0.74 \\
\hline NT & 13948 & $1120(8.0 \%)$ & $0.71(0.48-1.03)$ & 0.07 \\
\hline QLD & 163274 & $13696(8.4 \%)$ & $0.80(0.60-1.05)$ & 0.19 \\
\hline SA & 66509 & $8624(13.0 \%)$ & $0.75(0.55-1.02)$ & 0.59 \\
\hline TAS & 18795 & $1881(10.0 \%)$ & $0.97(0.69-1.37)$ & 0.64 \\
\hline VIC & 230652 & $23299(10.1 \%)$ & $0.84(0.64-1.11)$ & 0.33 \\
\hline WA & 61058 & $6409(10.5 \%)$ & $0.83(0.61-1.12)$ & 0.48 \\
\hline
\end{tabular}

$A C T=$ Australian Capital Territory; ANZROD = Australian and New Zealand Intensive Care Risk of Death; IRSAD = Index of Relative Socio-Economic Advantage and Disadvantage; NSW = New South Wales; NT = Northern Territory; $\mathrm{QLD}=$ Queensland; $\mathrm{SA}=$ South Australia; TAS = Tasmania; VIC = Victoria; $W A=$ Western Australia. ${ }^{*}$ Excludes IHT's defined by the referring unit (primary mortality analysis).

bear when faced with a health crisis. While this has been previously described in surgical subspecialty fields and for patients with cancer, this is the first study to highlight this issue in the Australian critical care literature. ${ }^{29-35}$

There is little Australian literature describing regional/rural critical care services, and the support they provide to regional hospitals. Two exceptions are a before and after observational study examining the introduction of an ICU telemedicine intervention in regional Victoria, which demonstrated a reduced need for IHTs, and a prospective observational study of emergency department (ED) presentations, also in rural Victoria, which demonstrated the breadth of presentation and interventions that were required in regional EDs was not dissimilar to that in tertiary hospitals. ${ }^{36,37}$ Their conclusion that regional/rural hospitals provide a surprising amount of critical care support - is not dissimilar to the findings in our data. ${ }^{36}$

There are implications in these data for the training of intensive care specialists. Despite the differences between regional/rural ICUs and

through cancellation of elective surgery in the setting of pandemic illness. The surprisingly high number of patients admitted to regional/rural ICUs with a capital city residential postcode may reflect tourists. Nevertheless, this emphasises the difference in caseload that regional/rural and metropolitan ICUs encounter compared with tertiary ICUs.

The higher ICU readmission rate seen in regional/rural ICUs may reflect the geographical isolation of the units and the lack of other health care facilities to which a patient can present. An alternative explanation, however, is that the high readmission rate points to a lack of primary health access and/or engagement and subsequent poorly managed chronic disease results in a frequent need for ICU readmission. $5,21,28$

The high rates of IHTS, while not unexpected, underline the costs (both personal, in terms of displacement from home and family, and economic) that regional Australians tertiary ICUs that these data highlight, current trainees are required to spend only 3 months in a regional/rural hospital. This time is not necessarily within an ICU. Many trainees are seeking, and receiving, retrospective recognition for time spent as a junior doctor in a regional hospital, yet it seems unlikely that this is adequate preparation. ${ }^{38}$ The need for intensive care medicine to expand into regional and regional/rural Australia to support both acute hospital servicing and to accommodate an increasing number of trainees has been recognised and is strengthened by these data. ${ }^{31,39}$ The issues around ensuring adequate training time in regional/rural centres are not unique to intensive care medicine and there are calls from other specialties, both within Australia and internationally, to ensure that specialist clinicians receive an appropriately broad training experience. ${ }^{40-42}$

The major strength of this study is the large, multicentre database from which the data are drawn. The APD data 


\section{ORIGINAL ARTICLES}

Figure 3. Mortality $(95 \% \mathrm{Cl})$ by hospital type adjusted for illness severity, socio-economic status, admission year, and jurisdiction

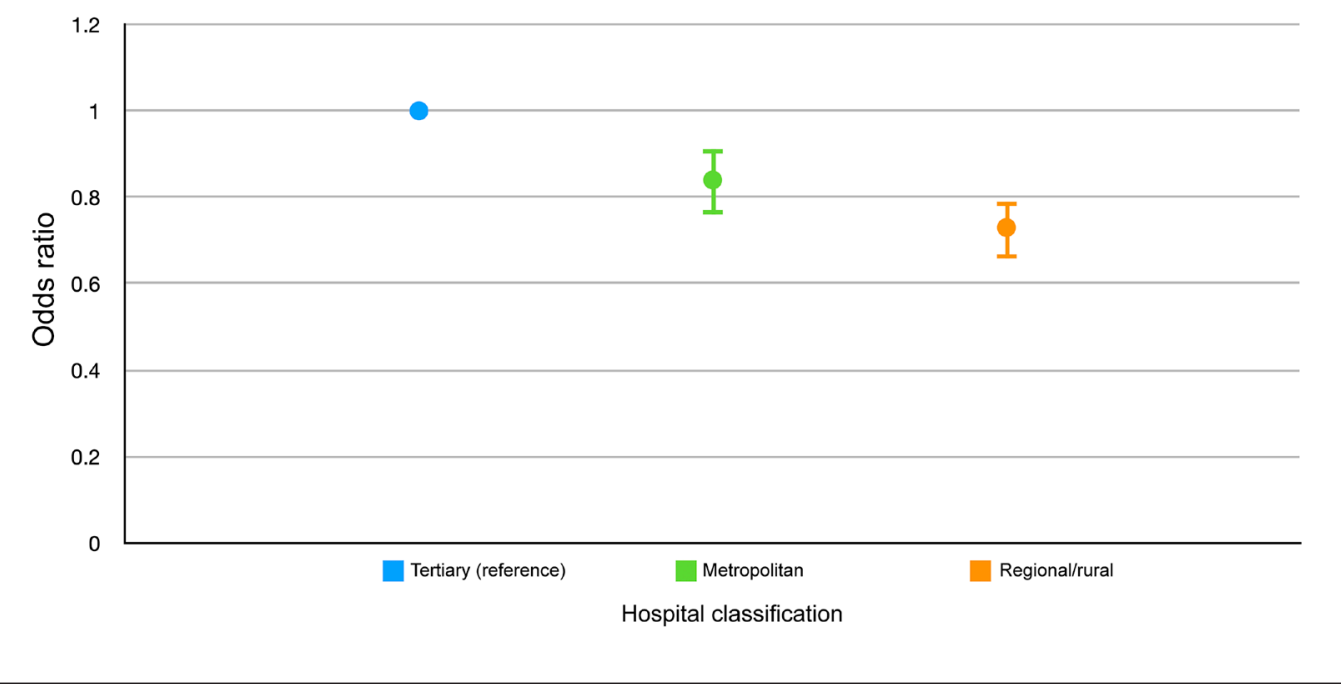

resourcing and processes of care in regional/rural ICUs, to better quantify the impediments to accessing ICU admission, teasing out the reasons for the high readmission rate to regional/rural ICUs, the role that regional/rural ICUs play in resuscitating the critically ill patient before $\mathrm{IHT}$, exploring further the impact of tourists on resource demands in regional/rural ICUs and, finally, identifying the barriers to training future intensivists and in recruiting intensivists to fill positions in regional/ rural ICUs. covered a sampling period exceeding 10 years, and incorporated admission data from 103 ICUs representing every state and territory, providing strong external validity. It is the first study to describe the characteristics and outcomes of regional/rural ICUs and provides important benchmarking.

The study has limitations. First, the population described is unique to Australia and may not represent the clinical practices, hospital resourcing, or geographical dispersion of population in other countries. Second, in a dataset of this size, it is inevitable that differences between groups may be statistically significant without necessarily being clinically relevant nor translate into an important patientcentred outcome. Third, the APD does not include cardiac care beds that may be co-located with ICUs and which regional/rural intensivists may oversee, which is thought to be more common in regional areas where fewer resources exist. As a result the contribution of a regional/rural ICU may be underestimated in this dataset. Finally, it is not possible with the current dataset to match those patients transferred from a regional/rural unit to a higher level of care, which may affect mortality outcomes, since the sickest patients who have a higher mortality risk are probably more likely to be transferred. We have attempted to mitigate this bias through multiple sensitivity analyses variably excluding IHTs and the result appears robust.

Future studies should focus on further elucidation of the apparent survival benefit of living in a remote area which necessarily includes describing workforce characteristics,

\section{Conclusion}

These data highlight the importance of regional/rural ICUs in supporting regional Australia, and they are topical, given media reporting around the quality of health care delivered at regional hospitals. ${ }^{16}$ It is the first study to describe the role of regional/rural ICUs in Australia in supporting critically ill patients and highlights the important role that regional/ rural ICUs perform in supporting the regional hospital where they are sited. Mortality outcomes in regional/rural ICUs are at least as good and possibly better than those in tertiary centres.

Acknowledgements: We acknowledge the assistance of Greg McAnulty for his thoughtful review and thorough proofreading.

In addition, the authors and the ANZICS CORE management committee would like to thank clinicians, data collectors and researchers at the following contributing sites: Albury Base Hospital ICU, Alfred Hospital ICU, Alice Springs Hospital ICU, Armadale Health Service ICU, Austin Hospital ICU, Ballarat Health Services ICU, Bankstown-Lidcombe Hospital ICU, Bathurst Base Hospital ICU, Bendigo Health Care Group ICU, Blacktown Hospital ICU, Box Hill Hospital ICU, Bunbury ICU, Bundaberg Base Hospital ICU, Caboolture Hospital ICU, Cairns Base Hospital ICU, Calvary Hospital (Canberra) ICU, Campbelltown Hospital ICU, Canberra Hospital ICU, Central Gippsland Health Service ICU, Coffs Harbour Health Campus ICU, Concord Hospital (Sydney) ICU, Dandenong Hospital ICU, Dubbo Base Hospital ICU, Fairfield Hospital ICU, Fiona Stanley, Flinders Medical Centre ICU, Footscray Hospital ICU, Frankston Hospital ICU, Fremantle Hospital ICU, Geelong Hospital ICU, Gold Coast University Hospital ICU, Gosford Hospital ICU, 


\section{ORIGINAL ARTICLES}

Goulburn Base Hospital ICU, Goulburn Valley Health ICU, Grafton Base Hospital ICU, Griffith Base Hospital ICU, Hervey Bay Hospital ICU, Hornsby Ku-ring-gai Hospital ICU, Ipswich Hospital ICU, John Hunter Hospital ICU, Latrobe Regional Hospital ICU, Launceston General Hospital ICU, Lismore Base Hospital ICU, Liverpool Hospital ICU, Logan Hospital ICU, Lyell McEwin Hospital ICU, Mackay Base Hospital ICU, Manly Hospital and Community Health ICU, Manning Rural Referral Hospital ICU, Maroondah Hospital ICU, Mater Adults Hospital (Brisbane) ICU, Modbury Public Hospital ICU, Monash Medical Centre-Clayton Campus, Mount Isa Hospital ICU, Nambour General Hospital ICU, Nepean Hospital ICU, North West Regional Hospital (Burnie), Northeast Health Wangaratta ICU, Orange Base Hospital ICU, Peter MacCallum Cancer Institute ICU, Port Macquarie Base Hospital ICU, Prince of Wales Hospital (Sydney) ICU, Princess Alexandra Hospital ICU, Queen Elizabeth II Jubilee Hospital ICU, Redcliffe Hospital ICU, Repatriation General Hospital (Adelaide), Robina Hospital ICU, Rockhampton Hospital ICU, Rockingham General Hospital ICU, Royal Adelaide Hospital ICU, Royal Brisbane and Women's Hospital ICU, Royal Darwin Hospital ICU, Royal Hobart Hospital ICU, Royal Melbourne Hospital ICU, Royal North Shore Hospital ICU, Royal Perth Hospital ICU, Royal Prince Alfred Hospital ICU, Shoalhaven Hospital ICU, Sir Charles Gairdner Hospital ICU, South West Healthcare (Warrnambool) ICU, St George Hospital (Sydney) ICU, St George Hospital (Sydney) ICU2, St Vincent's Hospital (Melbourne) ICU, St Vincent's Hospital (Sydney) ICU, Sunshine Coast Hospital ICU, Sunshine Hospital ICU, Sutherland Hospital and Community Health Services, Tamworth Base Hospital ICU, The Northern Hospital ICU, The Prince Charles Hospital ICU, The Queen Elizabeth Hospital (Adelaide) ICU, The Townsville Hospital ICU, Toowoomba Hospital ICU, Tweed Heads District Hospital ICU, Wagga Wagga Base Hospital and District Health Service, Western District Health Service (Hamilton), Westmead Hospital ICU, Wimmera Health Care Group (Horsham) ICU, Wollongong Hospital ICU, Wyong Hospital ICU.

\section{Competing interests}

None declared.

\section{Author details}

Paul Secombe 1,2,3,4

Alex Brown ${ }^{5,6}$

Michael Bailey ${ }^{3}$

Edward Litton ${ }^{4,7}$

David Pilcher $3,4,8$

1 Intensive Care Unit, Alice Springs Hospital, Alice Springs, NT, Australia.

2 School of Medicine, Flinders University, Adelaide, SA, Australia.

3 Australian and New Zealand Intensive Care Research Centre, School of Public Health and Preventive Medicine, Monash University, Melbourne, VIC, Australia.
4 Australian and New Zealand Intensive Care Society Centre for Outcome and Resource Evaluation, Melbourne, VIC, Australia.

5 Aboriginal Health Equity, South Australian Health and Medical Research Institute (SAHMRI), Adelaide, SA, Australia.

6 Faculty of Health and Medical Sciences, University of Adelaide, Adelaide, SA, Australia.

7 Intensive Care Unit Fiona Stanley Hospital, Perth, WA, Australia.

8 Department of Intensive Care, The Alfred Hospital, Melbourne, VIC, Australia.

Correspondence: paul.secombe@nt.gov.au

\section{References}

1 Australian Bureau of Statistics. Regional population growth, Australia, 2017-18 [Cat. No. 3218.0] https://www.abs.gov.au/ AUSSTATS/abs@.nsf/mf/3218.0 (viewed Sept 2020).

2 Trading Economics. Australia - rural land area (sq km), 2020. https://tradingeconomics.com/australia/rural-land-area-sq-kmwb-data.html (viewed Sept 2020).

3 Australian Institute of Health and Welfare. Rural and remote health 2017 https://www.aihw.gov.au/reports/rural-remoteaustralians/rural-remote-health/contents/summary (viewed Sept 2020).

4 Joynt KE, Harris Y, Orav EJ, Jha AK. Quality of care and patient outcomes in critical access rural hospitals. JAMA 2011; 306: 45-52.

5 Australian Institute of Health and Welfare. Survey of Health Care: selected findings for rural and remote Australians, 2018 [Cat. No. PHE 220]. https://www.aihw.gov.au/reports/ruralremote-australians/survey-health-care-selected-findings-ruralremote/contents/summary (viewed Sept 2020).

6 Secombe PJ, Brown A, Bailey MJ, Pilcher D. Equity for Indigenous Australians in intensive care. Med J Aust 2019; 211: 297-9.

7 Hicks P, Huckson S, Fenney E, et al. The financial cost of intensive care in Australia: a multicentre registry study. Med J Aust 2019; 211: 324-5.

8 Australian and New Zealand Intensive Care Society Centre for Outcomes and Resource Evaluation. ANZICS CORE annual report 2017. https://www.anzics.com.au/wp-content/ uploads/2018/10/ANZICS-CORE-Annual-Report-2017.pdf (viewed Sept 2020).

9 von Elm E, Altman DG, Egger M, et al. The Strengthening the Reporting of Observational Studies in Epidemiology (STROBE) statement: guidelines for reporting observational studies. Lancet 2007; 370: 1453-7.

10 Australian and New Zealand Intensive Care Society Centre for Outcomes and Resource Evaluation. APD data dictionary: ANZICS CORE - Adult patient database, version 5.10. Melbourne, VIC: ANZCIS CORE, 2017. https://www.anzics. com.au/wp-content/uploads/2018/08/ANZICS-APD-Dictionary. pdf (viewed Sept 2020).

11 Knaus WA, Wagner DP, Draper EA, et al. The APACHE III 


\section{ORIGINAL ARTICLES}

prognostic system. Risk prediction of hospital mortality for critically ill hospitalized adults. Chest 1991; 100: 1619-36.

12 Pilcher D, Paul E, Bailey M, Huckson S. The Australian and New Zealand Risk of Death (ANZROD) model: getting mortality prediction right for intensive care units. Crit Care Resusc 2014; 16: 3-4.

13 Paul E, Bailey M, Kasza J, Pilcher D. The ANZROD model: better benchmarking of ICU outcomes and detection of outliers. Crit Care Resusc 2016; 18: 25-36.

14 Australian Bureau of Statistics. Technical paper: Socio-Economic Indexes for Areas (SEIFA) 2011. Canberra: Commonwealth Government of Australia; 2013.

15 Hugo Centre for Population and Housing, University of Adelaide. Accessibility/Remoteness Index of Australia (ARIA) 2018. https://www.adelaide.edu.au/hugo-centre/spatial_data/ aria/ (viewed Sept 2020).

16 Australian Broadcasting Corporation. Four Corners: Health hazard. $A B C$ 2019; 9 Sept. https://www.abc.net.au/4corners/ health-hazard/11493580 (viewed Sept 2020).

17 Andreasyan K, Hoy WE. Patterns of mortality in Indigenous adults in the Northern Territory, 1998-2003: are people living in more remote areas worse off? Med J Aust 2009; 190: 307-11.

18 Phillips A. Health status differentials across rural and remote Australia. Aust J Rural Health 2009; 17: 2-9.

19 Carson E, Sharmin S, Maier AB, Meij JJ. Comparing indigenous mortality across urban, rural and very remote areas: a systematic review and meta-analysis. Int Health 2018; 10: 219-27.

20 Jacobs J, Peterson KL, Allender S, et al. Regional variation in cardiovascular mortality in Australia 2009-2012: the impact of remoteness and socioeconomic status. Aust N Z J Public Health 2018; 42: 467-73.

21 Secombe P, Brown A, McAnulty G, Pilcher D. Aboriginal and Torres Strait Islander patients requiring critical care: characteristics, resource use, and outcomes. Crit Care Resusc 2019; 21: 200-11.

22 Dare AJ, Ng-Kamstra JS, Patra J, et al. Deaths from acute abdominal conditions and geographical access to surgical care in India: a nationally representative spatial analysis. Lancet Glob Health 2015; 3: e646-53.

23 Secombe P, Planche Y, Athan E, Ollapallil J. Critical care burden of skin and soft tissue infection in Central Australia: More than skin deep. Aust J Rural Health 2019; 27: 550-6.

24 Tansley G, Schuurman N, Bowes M, et al. Effect of predicted travel time to trauma care on mortality in major trauma patients in Nova Scotia. Can J Surg 2019; 62: 123-30.

25 Teng TH, Katzenellenbogen JM, Hung J, et al. Rural-urban differentials in 30-day and 1-year mortality following first-ever heart failure hospitalisation in Western Australia: a populationbased study using data linkage. BMJ Open 2014; 4: e004724.

26 Secombe PJ, Chiang PY, Pawar B; Alice Springs Hospital RenalICU Research Group. Resource use and outcomes in patients with dialysis-dependent chronic kidney disease admitted to intensive care. Intern Med J 2019; 49: 1252-61.
27 Secombe PJ, Moynihan G, McAnulty G; Alice Springs Hospital Renal-ICU Research Group. Long term outcomes of dialysis dependent chronic kidney disease patients requiring critical care: an observational matched cohort study. Intern Med J 2020; doi: 10.1111/imj.14764 [Epub ahead of print].

28 Secombe PJ, Brown A, Bailey MJ, Pilcher D. Equity for Indigenous Australians in intensive care. Med J Aust 2019; 211: 297-9.

29 Rankin SL, Hughes-Anderson W, House AK, et al. Costs of accessing surgical specialists by rural and remote residents. ANZ J Surg 2001; 71: 544-7.

30 Martin-McDonald K, Rogers-Clark C, Hegney D, et al. Experiences of regional and rural people with cancer being treated with radiotherapy in a metropolitan centre. Int J Nurs Pract 2003; 9: 176-82.

31 Peake SL, Judd N. Supporting rural community-based critical care. Curr Opin Crit Care 2007; 13: 720-4.

32 Gordon L, Ferguson M, Chambers S, Dunn J. Fuel, beds, meals and meds: out-of-pocket expenses for patients with cancer in rural Queensland. Cancer Forum 2009; 33: 1-7.

33 O'Connor TM, Hanks HA, Elcock MS, et al. The medical and retrieval costs of road crashes in rural and remote northern Queensland, 2004-2007: findings from the Rural and Remote Road Safety Study. Med J Aust 2009; 190: 54-6.

34 Moffatt JJ, Eley DS. The reported benefits of telehealth for rural Australians. Aust Health Rev 2010; 34: 276-81.

35 Quinn L, Read D. Paediatric surgical services in remote northern Australia: an integrated model of care. ANZ J Surg 2017; 87: 784-8.

36 Baker T, Dawson SL. Small rural emergency services still manage acutely unwell patients: a cross-sectional study. Emerg Med Australas 2014; 26: 131-8.

37 Panlaqui OM, Broadfield E, Champion R, et al. Outcomes of telemedicine intervention in a regional intensive care unit: a before and after study. Anaesth Intensive Care 2017; 45: 605-10.

38 College of Intensive Care Medicine of Australia and New Zealand. Guide to CICM training: trainees. Melbourne, VIC: CICM, 2015. http://cicm.org.au/CICM_Media/CICMSite/ CICM-Website/Trainees/Training\%20Program/Guide-to-CICMTraining_Trainees-(April2015).pdf (viewed Sept 2020).

39 Board of the College of Intensive Care Medicine of Australia and New Zealand. Capacity to train and the intensive care workforce. Crit Care Resusc 2019; 21: 158-61.

40 Mohr NM, Collier J, Hassebroek E, Groth H. Characterizing critical care physician staffing in rural America: a description of lowa intensive care unit staffing. J Crit Care 2014; 29: 194-8.

41 Sweigart JR, Aymond D, Burger A, et al. Characterizing hospitalist practice and perceptions of critical care delivery. J Hosp Med 2018; 13: 6-12.

42 Bappayya S, Chen F, Alderuccio M, Schwalb H. Caseload distribution of general surgeons in regional Australia: is there a role for a rural surgery sub-specialization? ANZ J Surg 2019; 89: $672-6$. 